Supplemental File for:

\title{
Anatexis, cooling, and kinematics during orogenesis: Miocene development of the Himalaya metamorphic core, east-central Nepal
}

\author{
Kyle P. Larson', Dawn A. Kellett ${ }^{2}$, John M. Cottle ${ }^{3}$, Jess King ${ }^{4}$, Graham Lederer ${ }^{3,},{ }^{,}$Santa Man Rai ${ }^{6}$ \\ 'Earth and Environmental Sciences, University of British Columbia Okanagan, FIP353-3247 University Way, Kelowna, \\ British Columbia, V1V 1V7, Canada \\ ${ }^{2}$ Geological Survey of Canada, 601 Booth Street, Ottawa, ON K1A 0E8, Canada. \\ ${ }^{3}$ Department of Earth Science, University of California, Santa Barbara, Santa Barbara, CA, 93106-9630, USA \\ ${ }^{4}$ Department of Earth Sciences, The University of Hong Kong, Pokfulam Road, Hong Kong \\ *Present address: Department of Earth, Atmospheric and Planetary Sciences, Massachusetts Institute of Technology, \\ 77 Massachusetts Avenue, 54-1126, Cambridge, MA, 02139-4307, USA \\ ${ }^{5}$ Department of Geology, Tri-Chandra Campus, Tribhuvan University, Kathmandu, Nepal
}

\section{Contents of this file}

Supplemental Figure 1

Supplemental Text 1

Supplemental Text 2

Supplemental Figure 2

Supplemental Figure 3

Supplemental Figure 4

\section{Additional Supporting Information (Files uploaded separately)}

Supplemental Tables 1 to 4

\section{Introduction}

The supporting information includes details of the U-Th/Pb and ${ }^{40} \mathrm{Ar} /{ }^{39} \mathrm{Ar}$ methodologies, $\mathrm{x}-$ ray maps of all monazite grains analyzed in this study, ${ }^{40} \mathrm{Ar} /{ }^{39} \mathrm{Ar}$ step heating inverse isochron plots, and U/Pb, U-Th/Pb, trace element, and ${ }^{40} \mathrm{Ar} /{ }^{39} \mathrm{Ar}$ step heating data tables. Methods are as described in the main text. The data tables (captions below) are available as separate Microsoft Excel files. 

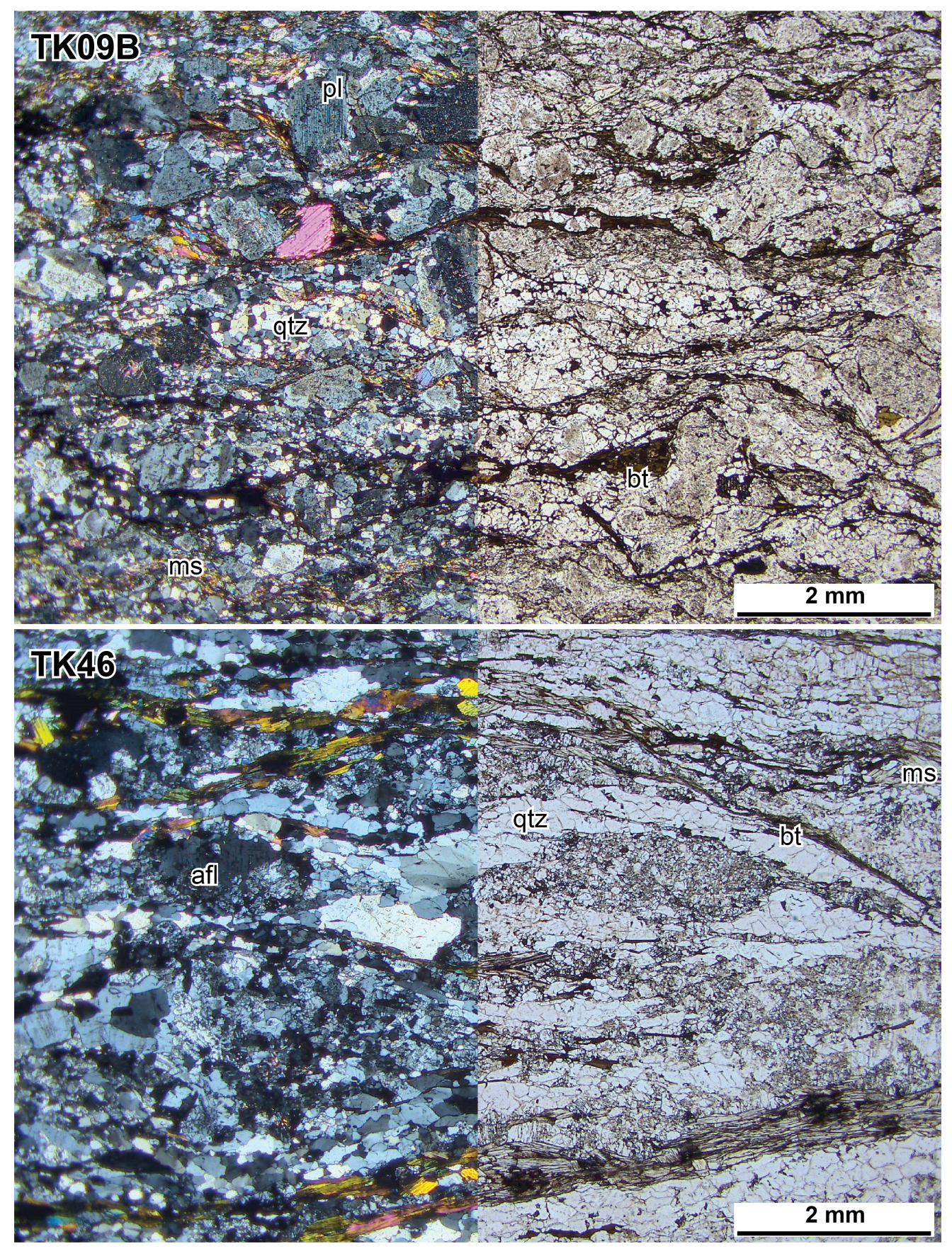

Supplemental Figure 1. Photomicrographs of specimens TK09B (top) and TK46 (bottom). Photomicrographs shown are halved between crossed polarized light (left) and plane polarized light (right). ms - muscovite, bt - biotite, pl - plagioclase, qtz - quartz, afl - alkali feldspar 
Supplemental Text 1: U-Th/Pb Geochronology Methods

Zircon from specimens PK051 and TK09A and TK09B were analyzed by LA-MC-ICPMS at the University of California in Santa Barbara. Full details of the analytical procedure can be found in Cottle et al. [2012; 2013]. U-Th/Pb analyses were conducted for 30s each using a spot diameter of $15 \mu \mathrm{m}$, a frequency of $4 \mathrm{~Hz}$, and $1.2 \mathrm{~J} / \mathrm{cm}^{2}$ fluence (equating to crater depths of $\sim 7$ $\mu \mathrm{m})$. Data reduction, including corrections for baseline, instrumental drift, mass bias, downhole fractionation, and uncorrected age calculations, and concentration calculations were performed using lolite version 2.5. Full details of the data reduction methodology can be found in Paton et al. [2010] and Cottle et al. [2012]. Age data were plotted using Isoplot v.3.7 [Ludwig, 2003] and Redux version 2.20.39 [Bowring et al., 2011].

Monazite from specimen PK199 was analyzed using the same LA-MC-ICPMS setup described above, except that a portion of the analyte was directed to an Agilent 7700S Quadrupole ICPMS to measure trace element abundances. Full details of the 'LASS' analytical procedure can be found in Kylander-Clark et al. [2013]. U-Th/Pb analyses on monazite were conducted for 20s each using a $7 \mu \mathrm{m}$ diameter spot, a frequency of $3 \mathrm{~Hz}$, and $0.75 \mathrm{~J} / \mathrm{cm}^{2}$ fluence (equating to crater depths of $\sim 8 \mu \mathrm{m}$ ). Isotope ratio data were reduced as outlined above for zircon. Trace element data were reduced using the 'Trace Elements' data reduction scheme in lolite version 2.5 .

$\mathrm{U} / \mathrm{Pb}$ zircon measurements were made over two sessions. During both sessions a primary reference material, zircon "91500" $\left(1065 \mathrm{Ma}{ }^{206} \mathrm{~Pb} /{ }^{238} \mathrm{U}\right.$ isotope dilution-thermal ionization mass spectrometry age [Wiedenbeck et al., 1995], was employed to monitor and correct for mass bias as well as $\mathrm{Pb} / \mathrm{U}$ down-hole fractionation. To monitor data accuracy, a secondary reference zircon "GJ1" (601.7 $\pm 1.3 \mathrm{Ma}$, D. Condon unpublished ID-TIMS age) was analyzed concurrently (once every five unknowns) and mass bias- and fractionation-corrected based on measured isotopic ratios of the primary reference material. During the first analytical session (in which PK051 and TK09A were run), repeat analyses of GJ-1 gave a weighted mean ${ }^{206} \mathrm{~Pb} /{ }^{238} \mathrm{U}$ age of $596 \pm 3 \mathrm{Ma}$, mean square weighted deviation $(M S W D)=1.9$. In the second session (in which TK09B was run) repeat analyses of GJ-1 gave a weighted mean ${ }^{206} \mathrm{~Pb} /{ }^{238} \mathrm{U}$ age of $600 \pm 3$, MSWD $=1.1$.

For U-Th/Pb monazite data, a primary reference material, "44096" (424 Ma Pb/U isotope dilution-thermal ionization mass spectrometry age [Aleinikoff et al., 2006]) was employed to monitor and correct for mass bias as well as $\mathrm{Pb} / \mathrm{U}$ and $\mathrm{Pb} / \mathrm{Th}$ down-hole fractionation. To monitor data accuracy, a secondary reference monazite "FC-1" (55.7 $\pm 1 \mathrm{Ma}{ }^{206} \mathrm{~Pb} /{ }^{238} \mathrm{U}$, ID-TIMS ages [Horstwood et al., 2003], was analyzed concurrently (once every five unknowns) and mass bias- and fractionation-corrected based on measured isotopic ratios of the primary reference material. During the analytical period, repeat analyses of FC-1 gave a weighted mean ${ }^{206} \mathrm{~Pb} /{ }^{238} \mathrm{U}$ age of $53.7 \pm 0.5 \mathrm{Ma}$, mean square weighted deviation $(\mathrm{MSWD})=1.9$, and $\mathrm{a}$ weighted mean ${ }^{208} \mathrm{~Pb} /{ }^{232} \mathrm{Th}$ age of $57.0 \pm 1.0 \mathrm{Ma}, \mathrm{MSWD}=1.6(2 \sigma)(\mathrm{n}=26)$.

Monazite trace element concentrations were normalized to an in-house reference "Baineriera" monazite and, based on the long-term reproducibility of multiple secondary reference monazites, are accurate to $3-5 \%$. All uncertainties are quoted at $2 \sigma$ and include contributions from the external reproducibility of the primary reference material for the ${ }^{207} \mathrm{~Pb} /{ }^{206} \mathrm{~Pb}$, ${ }^{206} \mathrm{~Pb} /{ }^{238} \mathrm{U}$ ratios, and ${ }^{208} \mathrm{~Pb} /{ }^{232} \mathrm{Th}$ ratios as well as trace element concentrations. The complete $\mathrm{U}-\mathrm{Th} / \mathrm{Pb}$ data are presented in Supplemental Tables 1 and 2, while trace element data are presented in Supplemental Table 3.

\section{$\underline{\text { References }}$}


Aleinikoff, J. N., W. S. Schenck, M. O. Plank, L. Srogi, C. M. Fanning, S. L. Kamo, and H. Bosbyshell (2006), Deciphering igneous and metamorphic events in high-grade rocks of the Wilmington Complex, Delaware: Morphology, cathodoluminescence and backscattered electron zoning, and SHRIMP U-Pb geochronology of zircon and monazite, GSA Bulletin, 118(1-2), 39-64, doi:10.1130/B25659.1.

Bowring, J. F., N. M. McLean, and S. Bowring (2011), Engineering cyber infrastructure for U-Pb geochronology: Tripoli and U-Pb_Redux, Geochem. Geophys. Geosyst., 12(6), doi:10.1029/2010GC003479.

Cottle, J. M., A. J. Burrows, A. R. Kylander-Clark, P. A. Freedman, and R. S. Cohen (2013), Enhanced sensitivity in laser ablation multi-collector inductively coupled plasma mass spectrometry, Journal of Analytical Atomic Spectrometry, 28(11), 1700-1706, doi:10.1039/c3ja50216c.

Cottle, J. M., A. R. Kylander-Clark, and J. C. Vrijmoed (2012), U-Th/Pb geochronology of detrital zircon and monazite by single shot laser ablation inductively coupled plasma mass spectrometry (SS-LA-ICPMS), Chemical Geology, 332-333, 136-147.

Horstwood, M. S. A., G. L. Foster, R. R. Parrish, S. R. Noble, and G. M. Nowell (2003), Common-Pb corrected in situ U?Pb accessory mineral geochronology by LA-MC-ICP-MS, Journal of Analytical Atomic Spectrometry, 18(8), 837-846, doi:10.1039/b304365g.

Kylander-Clark, A. R., B. R. Hacker, and J. M. Cottle (2013), Laser-ablation split-stream ICP petrochronology, Chemical Geology, 345, 99-112, doi:10.1016/j.chemgeo.2013.02.019.

Wiedenbeck, M., P. Alle, F. Corfu, W. L. Griffin, M. Meier, F. Oberli, A. Vonquadt, J. C. Roddick, and W. Speigel (1995), Three Natural Zircon Standards for U-Th-Pb, Lu-Hf, Trace-Element and Ree Analyses, Geostandards Newsletter, 19(1), 1-23, doi:10.1111/j.1751-

908X.1995.tb00147.x. 
Supplemental Text 2: ${ }^{40} \mathrm{Ar} /{ }^{39} \mathrm{Ar}$ Methodology

Mineral separation and sample preparation

${ }^{40} \mathrm{Ar} /{ }^{39}$ Ar step heat analyses

Sample preparation was carried out at the Geological Survey of Canada (GSC) in Ottawa. White mica was separated from specimens by flaking and hand picking directly from hand specimens. Mineral grains selected for dating ranged in size from 100-250 $\mu \mathrm{m}$ (Figure 8). In all cases the largest available grains that also passed a visual inspection in a Petri dish with ample amounts of ultra-pure ethyl alcohol under a microscope for purity (e.g., apparent lack of inclusions, mineral intergrowths or alteration) were selected for analysis. Individual mineral separates were loaded into 2-3 $\mathrm{mm}$-deep aluminum foil packets which were subsequently stacked vertically into $35-\mathrm{mm}$ long foil tubes and placed into the tubular holes of an aluminum cylinder. Several flux monitor grains of Fish Canyon tuff sanidine (FCT-SAN) (28.305 $\pm 0.0361 \sigma$ Ma; Renne et al., 2010) were loaded into each sample packet. J values were interpolated for samples situated between the spaced FCT-SAN monitor grains. GA 1550 biotite $(99.77 \pm 0.11$ $1 \sigma \mathrm{Ma}$, normalized to FCT-SAN at $28.305 \pm 0.0361 \sigma \mathrm{Ma}$ ) was used as a secondary standard to confirm the accuracy of the interpolations (Renne et al., 2010). The prepared can, GSC Irradiation \#67, was cadmium-shielded and irradiated for $160 \mathrm{MWH}$ in medium flux position 8B at the research nuclear reactor of McMaster University (MNR) in Hamilton, Ontario, Canada. Neutron fluence was $\sim 0.9 \times 10^{13}$ neutrons $/ \mathrm{cm}^{2}$ operating at a $2.5 \mathrm{MW}$ power level. Correction factors for typical interference species produced by thermal neutrons during irradiation are included in the footnote of Table DR4.

Analytical conditions and procedures

${ }^{40} \mathrm{Ar} /{ }^{39} \mathrm{Ar}$ step heat analyses

Following irradiation, multigrain aliquots were loaded into $1.5 \mathrm{~mm}$ diameter pits in a copper planchet and placed into an all-metal, ultra-high vacuum line at the Noble Gas laboratory of the Geological Survey of Canada (GSC), Ottawa. Individual grains were progressively heated and analyzed using a Photon Machines Ltd. Fusion $10.655 \mathrm{~W} \mathrm{CO}_{2}$ laser coupled to a $\mathrm{Nu}$ Instruments Noblesse multicollector mass spectrometer. Between one and three aliquots of each white mica mineral separate were step-heated over 10 heating steps, with replicates providing a gauge of within-sample variability/heterogeneity. Neutron flux was monitored using Fish Canyon tuff sanidine (FCT-SAN) (28.305 $\pm 0.0361 \sigma$ Ma; Renne et al., 2010), and interpolated for samples situated between spaced FCT-SAN monitor grains. GA 1550 biotite (Renne et al., 2010) was used as a secondary standard to confirm the accuracy of the interpolations. Laser energy was homogenized over a beam radius of $2 \mathrm{~mm}$ for a total of 40 sec, after which the released gas was exposed to SAES ${ }^{\mathrm{TM}} \mathrm{NP}-10\left(\sim 400^{\circ} \mathrm{C}\right)$ and HY-STOR ${ }^{\circledast} 201$ (room temperature) getters in the extraction line for six minutes. Following gettering, the sample gas was expanded into the mass spectrometer. The Nu Noblesse is a single-focusing, Nier-source, 75 magnetic sector multicollector noble gas spectrometer equipped with two quadrupole lens arrays. Ar ions were measured with a fixed array of three ETP ${ }^{\circledR}$ discrete dynode ion-counting multipliers. Data collection followed the measurement scheme MC-Y detailed in Kellett and Joyce (2014). Blanks were run every $4^{\text {th }}$ analysis, in an identical manner to unknowns. Air shots were analyzed every $10^{\text {th }}$ analysis to monitor efficiency and mass fractionation. Full results are included in Table DR4. Sensitivity of the Nu Noblesse at the time of analyses was 7.1-7.5 Amps/mol. Data collection, reduction, error propagation, age calculation and plotting were performed using the software MassSpec (version 7.93) (Deino, 2001) using the decay constant of Min et al. (2000). 


\section{References}

Deino, A.L., 2001. Users manual for Mass Spec v. 5.02. Berkeley Geochronology Center Special Publication 1a, $119 \mathrm{p}$.

Kellett, D.A. and Joyce, N., 2014. Analytical details of single- and multi-collection ${ }^{40} \mathrm{Ar} /{ }^{39} \mathrm{Ar}$ measurements for conventional step-heating and total fusion age calculation using the Nu Noblesse at the Geological Survey of Canada: analytical details. Geological Survey of Canada, Technical Note 8, 27 p., doi: 10.4095/293465.

Min, K.W., Mundil, R., Renne, P.R., and Ludwig, K.R., 2000, A test for systematic errors in Ar40/Ar-39 geochronology through comparison with U/Pb analysis of a 1.1-Ga rhyolite: Geochimica Et Cosmochimica Acta, v. 64, p. 73-98, doi: 10.1016/S0016-7037(99)00204-5. 
PK199 monazite $\mathrm{Y}(\mathrm{L} \alpha) \mathrm{x}$-ray maps

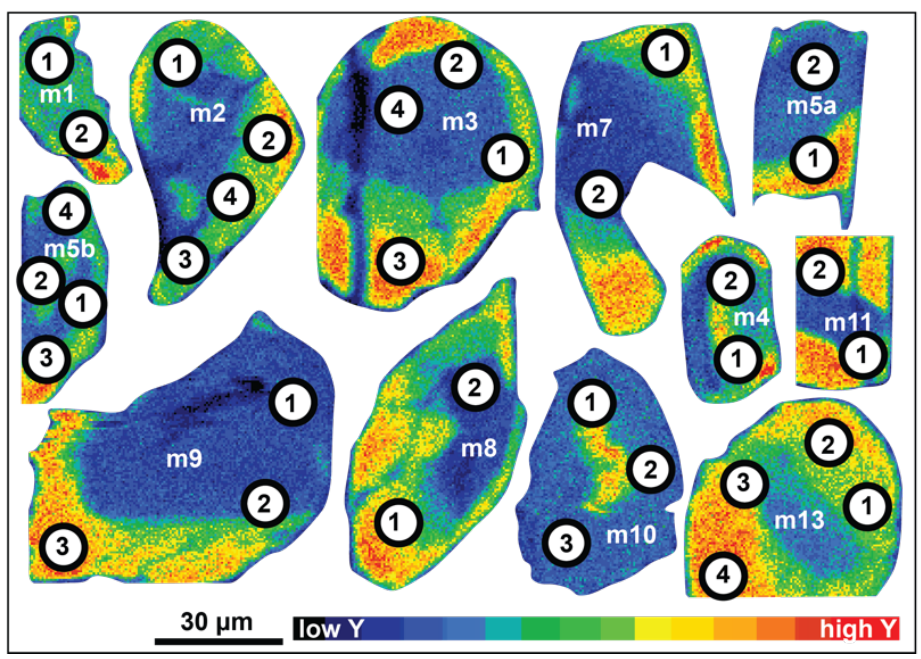

Supplemental Figure 2. X-ray maps of all monazite grains examined in PK199. Grain labels and spot numbers correspond to Supplemental Tables 2 and 3.

(Next Page) Supplemental Figure 3. Inverse isochron plots (ellipses are $1 \sigma$ ) for ${ }^{40} \mathrm{Ar} /{ }^{39} \mathrm{Ar}$ step heating analysis of specimens TK15, TK46, TK56, and TK40. Full data are presented in Supplemental Table 4. 

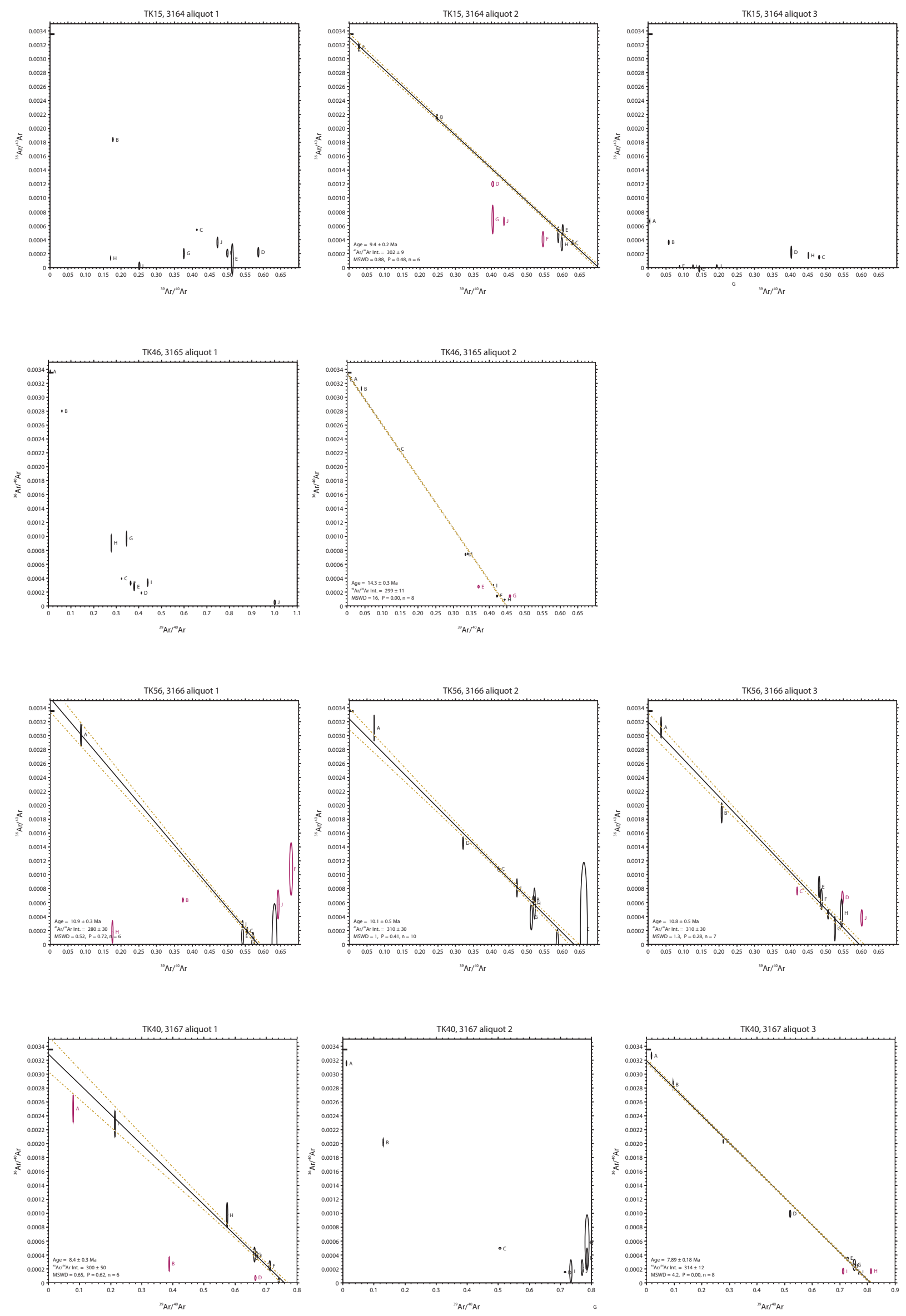


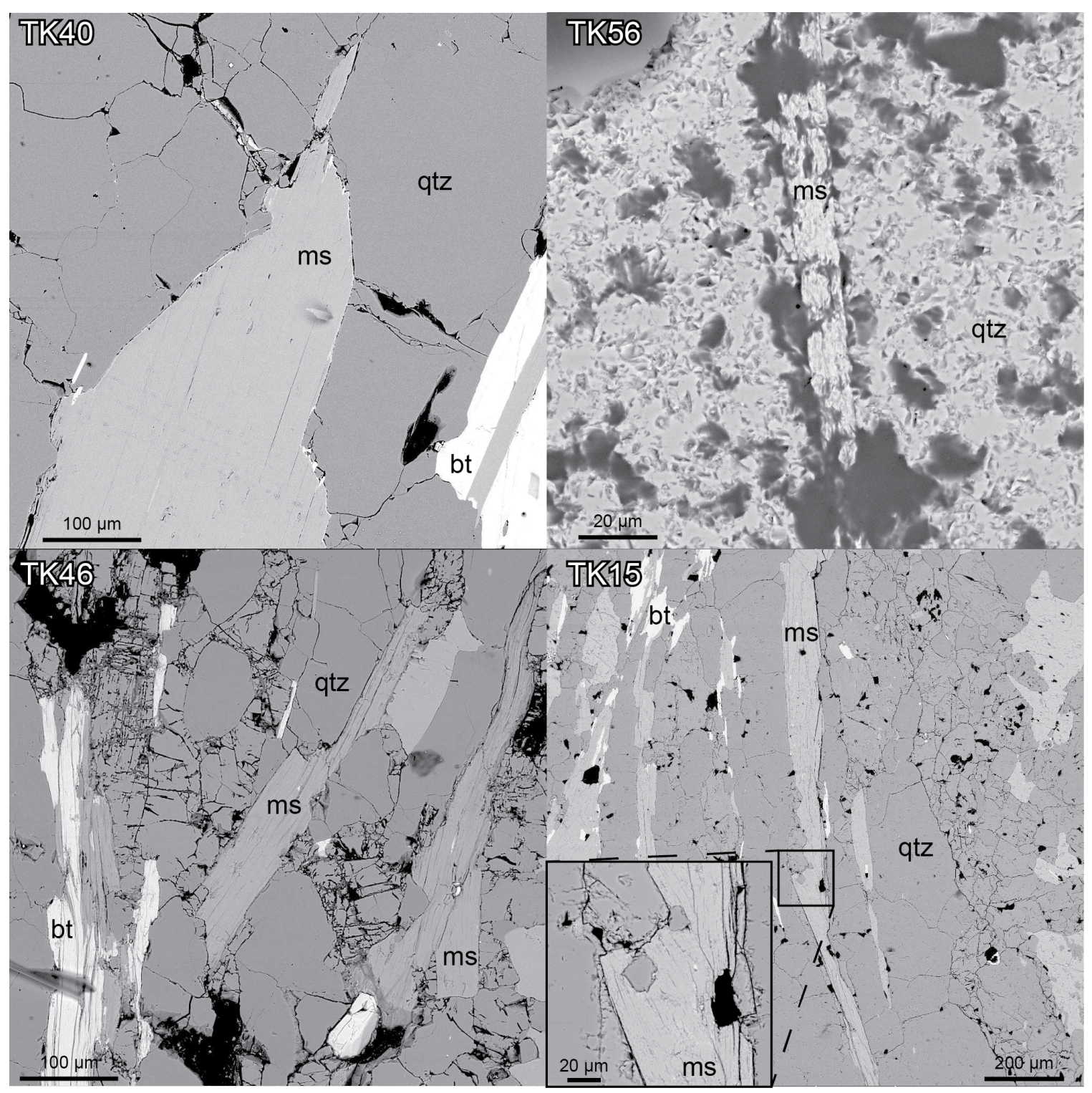

Supplemental Figure 4. Back-scattered electron images of representative muscovite grains from the specimens dated in this study. The polish for slide TK56 is very poor making imaging challenging. ms - muscovite; bt - biotite; qtz - quartz 
Supplemental Table 1. Zircon U/Pb Geochronology Data (separate file)

Supplemental Table 2. Monazite U-Th/Pb Geochronology Data (separate file)

Supplemental Table 3. Monazite Trace Element Data (separate file)

Supplemental Table 4. ${ }^{40} \mathrm{Ar} /{ }^{39} \mathrm{Ar}$ Thermochronology Step Data (separate file) 